\title{
PROTECTIVE EFFECTS OF NIFEDIPINE, VERAPAMIL AND DILTIAZEM AGAINST ACUTE ACETAMINOPHEN HEPATOTOXICITY IN ADULT MALE ALBINO RATS
}

\author{
Usama M. El-Barrany* and Ashraf M.F. Kamel** \\ Departments of Forensic Medicine \& Toxicology*; \\ and Histology ${ }^{\star \star}$, Faculty of Medicine, Cairo University
}

\section{INTRODUCTION}

Acetaminophen is one of the commonly prescribed over the-counter analgesic and antipyretic medications (Flaherty, 1998 and Abbott and Fraser, 1998). It is relatively safe and effective at therapeutic doses, but high doses of the drug cause fulminant liver necrosis in human and experimental animals (Matthews et al., 1996). Hepatotoxicity is thought to result from the cytochrome P450-mediated oxidation of acetaminophen to $\mathrm{N}$ acetyl-p-benzoquinone imine (NAPQI) which is highly reactive and is considered the toxic metabolite of acetaminophen (Harman et al., 1991). This highly reactive metabolite is scavenged by reduced glutathione $(\mathrm{GSH})$, leading to a decrease of hepatic GSH concentration after acetaminophen (Anundi et al., 1993). Depletion of GSH causes the remaining quinone to bind to cellular macromolecules leading to cell death by a cellular oxidative stress resulting in lipid peroxidation and changes in intracellular $\mathrm{Ca}^{2+}$ homeostasis (Cohen and Khairallah, 1997).

Acetaminophen-induced hepatic necrosis was first described in rats in an experimental toxicological study by Boyd and Bereczky (1966). Their histological observations were supplemented by those of Dixon et al. (1971) who studied the evolution of the lesion up to 28 days after administration, and found hydropic vacuolations, centrilobular necrosis, macrophage infiltration and regenerative activity with a rapid restoration to normal.

Intracellular calcium plays multiple roles, essential to the control of cellular functions (Boobis et al., 1990). Cytosolic $\mathrm{Ca}^{2+}$ concentration is controlled by active $\mathrm{Ca}^{2+}$ sequestration into intracellular stores which include mitochondria and the $\mathrm{Ca}^{2+}$ endoplasmic or sarcoplasmic reticulum, and by $\mathrm{Ca}^{2+}$ binding to intracellular proteins (calmodulin) (Orrenius et al., 1989). Thibault et al. (1991) suggested that influx of extracellular calcium into the cells could have a role in the genesis of hepatocyte injury by acetaminophen and Crenesse et al. (1999) demonstrated that calcium played an important role in hepatocyte damage. 
In vivo studies have shown that the intracellular $\mathrm{Ca}^{2+}$ concentration of hepatocytes markedly increases between 18 and $24 \mathrm{~h}$ after exposure, associated with hepatocyte necrosis (Landon et al,, 1986). Hepatocyte death can be prevented by calcium ethylene diamine tetra acetate (calcium EDTA) added to the culture medium during or after acetaminophen exposure (Beales et al., 1985). Bruschi and Priestly (1990). Experiments on isolated cells, have found that following exposure of the cells to lethal concentration of acetaminophen, there was a rapid and sustained rise in cytosolic $\mathrm{Ca}^{2+}$ which correlated with the subsequent loss of viability. Prevention of this rise in $\mathrm{Ca}^{2+}$, or its early restoration to normal levels prevents cell death (Boobis et al., 1989).

The $\mathrm{Ca}^{2+}$ channel blocking agents nifedipine (NF), verapamil $(V)$ and diltiazem (DL) represent a chemically heterogeneous group which binds different sites on voltage-dependent $\mathrm{Ca}^{2+}$ channels and reduces $\mathrm{Ca}^{2+}$ influx into the cells (Koleva and Stoytchev, 1995; Cobreros et al., 1997). Several investigators described protective effects of several calcium channel blocking agents against acetaminophen hepatotoxicity on biochemical grounds, but none demonstrated this protective effect histologically especially on the electron microscopical level (Landon et al., (1986) and El. louk-Achard et al., (1995).

The aim of this study was to clarify whether pretreatment with NF, $V$ and DL could prevent or diminish the occurrence of acetaminophen toxicity and to demonstrate these protective effects histologically by light and electron microscopic methods.

\section{MATERIALS AND METHODS}

\section{Test materials:}

Acetaminophen, NF and DL were purchased from Egyptian International Pharmaceutical Industries Company (EIPICO), Cairo, Egypt. Verapamil was purchased from The Arab Drug Company, Cairo, Egypt. Kits for aminotransferases, reduced glutathione, lipid peroxidation and cytochrome P450 were obtained from Boehringer Mannheim GmbH, Germany. Lastly, saline was supplied by the Nile Company for Pharmaceutical and Chemical Industries, Cairo, Egypt.

\section{Animals:}

One hundred and twenty eight adult male albino rats weighing 110$130 \mathrm{~g}$ were obtained from Helwan Breeding Farm, Cairo, Egypt. They were selected for use on the basis of adequate body weight gain and freedom from any clinical signs of disease or injury. The rats were housed in a metal-holding cage on bedding of wood chips "maximum of six rats per 
cage" in an animal house kept under laboratory conditions, and maintained on standard commercial food and water, ad libitum. Animals were marked by tail marking with indelible ink.

The rats were individually weighed and randomly assigned into eight equal groups of 16 rats each in such a way that there were no statistically significant differences among group body weight means.

- Group (1): The negative control group, where the rats were given $2 \mathrm{ml}$ normal saline.

- Group (2): The rats in this group were given acetaminophen in a dose of $850 \mathrm{mg} / \mathrm{kg}$. This dose equals one half of the oral median lethal dose (LD50) of acetaminophen rats according to Clarke (1974).

- Group (3): The rats in this group were given NF in a dose of $35 \mathrm{mg} / \mathrm{kg}$ (London et al., 1986).

- Group (4): The rats in this group were given $V$ in a dose of $15 \mathrm{mg} / \mathrm{kg}$ (Koleva and Stoytchev, 1991).

- Group (5): The rats in this group were given DL in a dose of $50 \mathrm{mg} / \mathrm{kg}$ (Thibault et al., 1991).

- Group (6): The rats in this group were given NF $(35 \mathrm{mg} / \mathrm{kg})$ one hour before acetaminophen $(850 \mathrm{mg} / \mathrm{kg})$.

- Group (7): The rats in this group were given $V(15 \mathrm{mg} / \mathrm{kg})$ one hour before acetaminophen $(850 \mathrm{mg} / \mathrm{kg})$.

- Group (8): The rats in this group were given $\mathrm{DL}(50 \mathrm{mg} / \mathrm{kg})$ one hour before acetaminophen $(850 \mathrm{mg} / \mathrm{kg})$.

Groups (3), (4) and (5) were considered positive controls.

The doses of NF, $V$ and DL represent one-tenth of the oral LD50 for rats. Acetaminophen and NF were dissolved in distilled water with a few drops of Tween-80, and $V$ and DL were dissolved in distilled water. All drugs were given once by the oral route through a gastric tube for all rats.

The animals were deprived of food four hours before acetaminophen administration because acetaminophen hepatotoxicity was found to be greater in fasted than fed rats (Lauterburg and Mitchell, 1982).

\section{Survival rates, Aminotransferases and liver weights:}

Ten rats from each group were chosen for this purpose as well as for histology. Survival was monitored for all rats for 24 hours after treatment. Blood samples were collected from the retro-bulbar venous plexus, through capillary tubes from surviving rats. The sera were separated by centrifuga- 
tion. Serum aspartate aminotransferase (AST) and serum alanine aminotransferase (ALT) were analyzed spectrophotometrically by the method of Reitman and Frankel (1957). The results were expressed as SigmaFrankel units / $\mathrm{ml}$. These rats were then killed by decapitation. Livers were excised rapidly, blotted dry and weighed. The results were expressed as $\mathrm{g}$ liver weight / $10 \mathrm{~g}$ body weight.

\section{Histology:}

Sections of the livers were fixed in $10 \%$ formol saline and embedded in paraffin for histological examination. The stain used was Harris' hematoxylin and eosin (H \& E) (Drury and Wallington, 1980).

For Transmission Electron Microscopy, a simplified method for tissue processing was used as described by Hayat (1970). Small pieces of the livers were taken and rinsed in $0.1 \mathrm{M}$ phosphate buffer, $\mathrm{pH} 7.2$. Approximately $1 \mathrm{~mm}^{3}$ liver pieces were trimmed and immediately fixed into $3 \%$ ice cold glutaraldehyde in $0.1 \mathrm{M}$ phosphate buffer and kept overnight at $4^{\circ} \mathrm{C}$. The tissue pieces were washed three times for 15 minutes in $0.1 \mathrm{M}$ phosphate buffer $\mathrm{pH} 7.2$ to remove traces of free glutaraldehyde.

Then the tissue pieces were further fixed in $1 \%$ osmium tetraoxide in $0.1 \mathrm{M}$ phosphate buffer for $5-6$ hours at $4^{\circ} \mathrm{C}$. After post fixation the tissues were washed again in $0.1 \mathrm{M}$ phosphate buffer; three times and were kept in buffer at $4^{\circ} \mathrm{C}$ overnight; to remove free osmium tetraoxide.

The tissues were dehydrated using ascending grades of acetone from $30,50,70,80,90,95,100 \%$, for 10 minutes $\times 2$ changes and then embedded in epoxy resin. Ultrathin sections were cut and stained with uranyl acetate and lead citrate and then examined under Zeiss EM 10C TEM using an accelerated voltage of $60 \mathrm{KV}$.

Hepatic reduced glutathione (GSH) levels,

\section{cytochrome P450 and lipid peroxidation :}

Six rats from each group were chosen for this purpose. These levels were determined 2 hours after treatment.

The levels of liver GSH (mcg/gm liver) were determined using the fluorimetric method of Hissin and Hiff (1976). A fluorescence spectrophotometer MPF-44B Perkin-Elmer was used.

Cytochrome $\mathrm{P} 450$ in microsomes ( $\mathrm{nmol} / \mathrm{mg}$ protein) was determined by the carbon monoxide difference spectra of dithionite-reduced microsomes using an extinction coefficient of $91 \mathrm{mM} 1^{-} \mathrm{cm} 1$ for A450- A490 (Omura and Sato, 1964). 
Lipid peroxidation in liver microsomes was determined by the thiobarbituric acid test of Buege and Aust (1978). The amount of thiobarbituric acidreactive substances formed was determined spectrophotometrically using a molar extinction coefficient of $1.56 \times 10^{-5} \mathrm{M}^{-1} \mathrm{CM}^{-1} 1$. The results were expressed as $\mathrm{nmol}$ malondialdehyde formed $/ \mathrm{mg}$ protein.

\section{Statistical analysis:}

The data were statistically analysed by Student's $t$-test. Results were expressed as means $\pm S D$. The minimum level of significance was considered to be $p<0.05$.

\section{RESULTS}

\section{Survival rates:}

Acetaminophen given as a single oral dose of $850 \mathrm{mg} / \mathrm{kg}$ resulted in $40 \%$ mortality during the first 24 hours after treatment. In animals pretreated with $N F, V$ and $\mathrm{DL}$, the mortality was significantly reduced to $10 \%$, $10 \%$ and $0 \%$ respectively. All rats of the control groups survived. (Fig. 1).

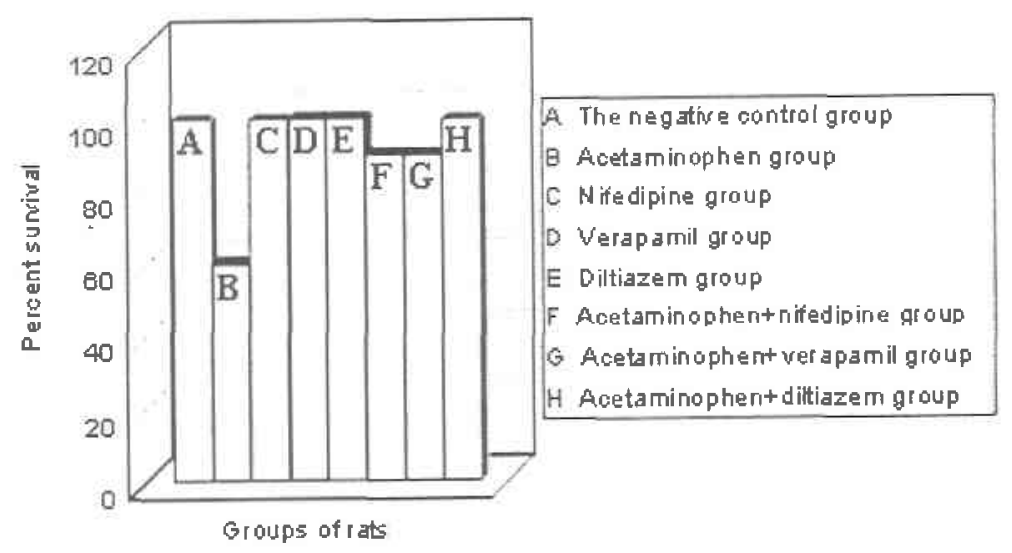

Fig. (1): Percent survival of the studied rat groups during the first 24 hours after treatment

\section{Serum aminotransferases}

Rats receiving NF, $V$ or $D L$ alone showed no significant changes in serum aminotransferases, while those receiving acetaminophen alone showed a significant elevation of both serum aminotransferases than the negative control rats. On the other hand, rats receiving NF, V or DL one hour before acetaminophen showed significant reductions of both serum aminotransferases than rats given acetaminophen alone (Table 1). 
Table (1): Mean \pm standard deviation (SD) of serum amino-transferases leveis in Sigma-Frankel units/ $\mathrm{ml}$ and their statistical significance in the studied groups of rats.

\begin{tabular}{|l|c|c|}
\hline \multirow{2}{*}{ Rat groups } & \multicolumn{2}{c|}{ Serum aminotransferases } \\
\cline { 2 - 3 } & $\begin{array}{c}\text { Serum Aspartate } \\
\text { Aminotransferase }\end{array}$ & $\begin{array}{c}\text { Serum Alanine } \\
\text { Aminotransferase }\end{array}$ \\
\hline The negative control group & $127 \pm 18.6$ & $38 \pm 5.6$ \\
\hline Acetaminophen group & $3125 \pm 486.8^{*}$ & $1013 \pm 194.3^{*}$ \\
\hline Nifedipine group & $124 \pm 15.5$ & $39 \pm 4.8$ \\
\hline Verapamil group & $125 \pm 16.9$ & $35 \pm 3.9$ \\
\hline Diltiazem group & $126 \pm 15.8$ & $36 \pm 4.9$ \\
\hline Acetaminophen +nifedipine group & $980 \pm 180.7^{*} \#$ & $269 \pm 45.4^{* \#}$ \\
\hline Acetaminophen +verapamil group & $860 \pm 140.3^{*} \#$ & $180 \pm 26.9^{*} \#$ \\
\hline Acetaminophen +diltiazem group & $710 \pm 112.4^{*} \#$ & $140 \pm 18.7^{*} \#$ \\
\hline
\end{tabular}

* Significant difference from the negative control group $(p<0.05)$. \# Significant difference from acetaminophen group $(p<0.05)$.

\section{Liver weights:}

Rats receiving NF, $V$ or $D L$ alone showed no significant changes in liver weights, while those receiving acetaminophen alone showed a significant increase of liver weights than the negative control rats. On the other hand, rats receiving NF, $V$ or $D L$ one hour before acetaminophen showed significant increases of liver weights than rats given acetaminophen alone (Table 2; Fig. 2). 
Table (2): Mean $\mathrm{t}$ standard deviation (SD) of liver weights in $\mathrm{gm} / 10 \mathrm{gm}$ body weight and their statistical significance in the studied groups of rats.

\begin{tabular}{|l|c|}
\hline \multicolumn{1}{|c|}{ Rat groups } & Mean \pm SD of Liver weights \\
\hline The negative control group & $0.79 \pm 0.02$ \\
\hline Acetaminophen group & $1.15 \pm 0.09 *$ \\
\hline Nifedipine group & $0.69 \pm 0.02$ \\
\hline Verapamil group & $0.71 \pm 0.03$ \\
\hline Diltiazem group & $0.67 \pm 0.01$ \\
\hline Acetaminophen +nifedipine group & $0.87 \pm 0.05 \#$ \\
\hline Acetaminophen + verapamil group & $0.85 \pm 0.04 \#$ \\
\hline Acctaminophen + diltiazem group & $0.81 \pm 0.03 \#$ \\
\hline
\end{tabular}

* Significant difference from the negative control group $(p<0.05)$.

\# Significant difference from acetaminophen group $(p<0.05)$.

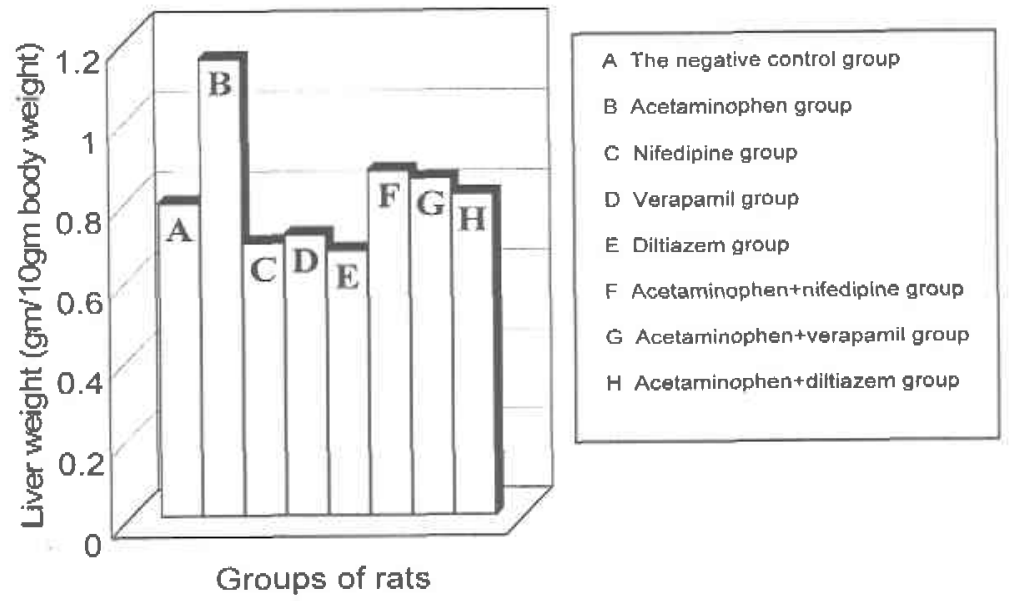

Fig. (2): Mean liver weights in gm/10gm body weight of the studied rat groups. 


\section{Hepatic reduced glutathione levels:}

Rats receiving NF, $V$ or $D L$ alone showed no significant changes in liver GSH, while those receiving acetaminophen alone showed a significant reduction of liver GSH than the negative control rats. On the other hand, rats receiving NF, $V$ or DL one hour before acetaminophen showed no significant elevations of liver GSH than rats given acetaminophen alone (Table 3; Fig. 3).

Table (3): Mean \pm standard deviation (SD) of hepatic reduced glutathione $(\mathrm{GSH})$ in $\mathrm{mcg} / \mathrm{gm}$ liver and their statistical significance in the studied groups of rats.

\begin{tabular}{|l|c|}
\hline \multicolumn{1}{|c|}{ Rat groups } & Mean \pm SD of Liver GSH \\
\hline The negative control group & $1230 \pm 80.4$ \\
\hline Acetaminophen group & $611 \pm 45.2^{*}$ \\
\hline Nifedipine group & $1273 \pm 91.6$ \\
\hline Verapamil group & $1299 \pm 76.4$ \\
\hline Diltiazem group & $1255 \pm 89.7$ \\
\hline Acetaminophen +nifedipine group & $661 \pm 49.5^{*}$ \\
\hline Acetaminophen + verapamil group & $655 \pm 50.8^{*}$ \\
\hline Acetaminophen + diltiazem group & $629 \pm 41.3^{*}$ \\
\hline
\end{tabular}

* Significant difference from the negative control group $(P<0.05)$

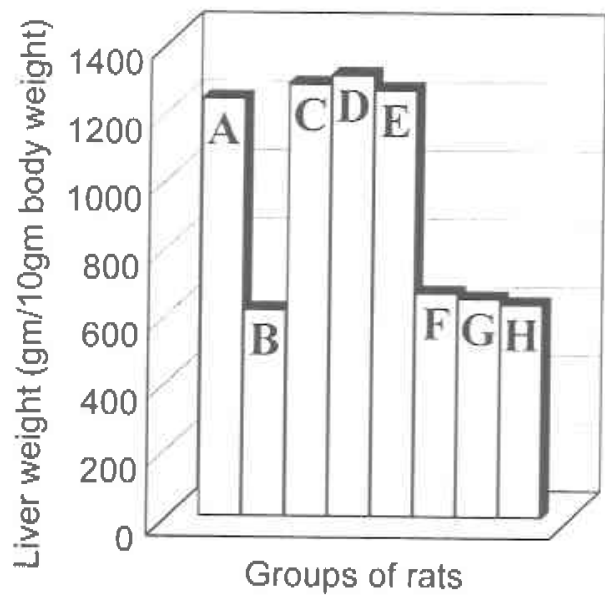

\begin{tabular}{l} 
A The negative control \\
B Acetaminophen group \\
C Nifedipine group \\
D Verapamil group \\
E Diltiazem group \\
F Acetaminophen+nifedipine \\
G Acetaminophen+verapamil \\
H Acetaminophen+diltiazem \\
\hline
\end{tabular}

Fig. (3): Mean hepatic reduced glutathione (GSH) in $\mathrm{mcg} / \mathrm{gm}$ liver of the studied rat groups. 


\section{Cytochrome $\mathbf{P 4 5 0}$ and lipid peroxidation:}

Nifedipine, given alone or in combination with acetaminophen showed a significant elevation of Cytochrome $\mathrm{P} 450$ than the negative control rats, while rats of all other groups showed no significant changes of Cytochrome P450 than rats of the negative control group.

On the other hand, DL given alone showed a significant reduction, of lipid peroxidation while NF or $\mathrm{V}$ given alone showed no significant changes in lipid peroxidation than the negative control rats. Acetaminophen, given alone or in combination with either NF or $V$ showed a significant elevation of lipid peroxidation than rats of the negative control group. Diltiazem given 1 hour before acetaminophen significantly reduced lipid peroxidation induced by acetaminophen (Table 4).

Table (4): Mean \pm standard deviation (SD) of Cytochrome P450 (nmol / $\mathrm{mg}$ protein) as well as lipid peroxidation (nmol malondialdehyde $/ \mathrm{mg}$ protein) and their statistical significance in the studied groups of rats.

\begin{tabular}{|l|c|c|}
\hline \multicolumn{1}{|c|}{ Rat groups } & $\begin{array}{c}\text { Mean } \pm \text { SD of } \\
\text { Cytochrome P450 }\end{array}$ & $\begin{array}{c}\text { Mean } \pm \text { SD of Lipid } \\
\text { Peroxidation }\end{array}$ \\
\hline The negative control group & $0.493 \pm 0.024$ & $0.298 \pm 0.009$ \\
\hline Acetaminophen group & $0.517 \pm 0.039$ & $0.452 \pm 0.014^{*}$ \\
\hline Nifedipine group & $0.675 \pm 0.015^{*}$ & $0.289 \pm 0.007$ \\
\hline Verapamil group & $0.511 \pm 0.027$ & $0.291 \pm 0.011$ \\
\hline Diltiazem group & $0.498 \pm 0.033$ & $0.204 \pm 0.005^{*}$ \\
\hline Acetaminophen + nifedipinc group & $0.694 \pm 0.037^{*}$ & $0.412 \pm 0.007^{*}$ \\
\hline Acetaminophen + verapanil group & $0.521 \pm 0.041$ & $0.401 \pm 0.014^{*}$ \\
\hline Acetaminophen + diltiazengroup & $0.513 \pm 0.046$ & $0.226 \pm 0.003^{*} \#$ \\
\hline
\end{tabular}

* Significant difference from the negative control group $(p<0.05)$.

\# Significant difference from acetaminophen group $(p<0.05)$. 


\section{Histological Changes:}

\section{A. At the light microscopical level:}

Animals treated with NF, V or DL alone (the positive controls) showed no histological changes as in the negative control rats (Figs. 4-a and 4-b), while, in animals that received acetaminophen alone, the hepatic portal tract area showed mononuclear cellular infiltration, congestion of central vein, esinophilic necrosis seen in the cytoplasm of peripheral hepatocytes with pyknosis of some nuclei and some destruction of the hepatic lobular architecture with sinusoidal dilatation (Figs. 5-a and 5-b).

Administration of NF 1 hour before acetaminophen led to some improvement in the liver tissue but there was still congestion of the central vein (CV), hydropic degeneration of hepatocytes which appeared vacuolated and mononuclear cellular infiltration at the portal tract (Figs. 6-a and 6-b).

Administration of $\vee 1$ hour before acetaminophen led also to improvement in the hepatic lobular architecture but there were still swollen hepatocytes with narrowed sinusoids, congestion of $\mathrm{CV}$ and mononuclear cellular infiltration at the portal tract (Figs. 7-a and 7-b).

Administration of $D L 1$ hour before acetaminophen led to more improvement in the liver tissue than NF or DL where there was patchy pathology in the form of few swollen hepatocytes, other peripheral degenerated hepatocytes which appeared vacuolated with dilatation of sinusoids between the degenerated hepatocytes (Figs. 8-a and 8-b).

\section{B. At the electron microscopy level:}

Again, liver sections from rats belonging to the positive control groups showed no abnormal histological changes as in the negative control rats (Fig. 9). Meanwhile, liver sections from the rats of group (2) which received acetaminophen only showed glycogen depletion and presence of large intracellular membrane bound vacuoles that often impinged on the nucleus (Figs. 10-a and 10-b). These large vacuoles appeared containing loosely-packed electron-dense amorphous material. They seemed to be formed by coalescence of vesicular dilatations in the smooth endoplasmic reticulum (SER) as there were communications between the smooth endoplasmic canalicular system and the large intracellular vacuoles. The plasma membranes of the affected hepatocytes were unapparent and it was often difficult to distinguish individual cell borders.

Liver sections of animals of group (6) which received NF one hour before acetaminophen showed smaller size of SER vacuolations (Fig. 11). Sections of group (7) animals which received $V$ one hour before acetaminophen showed even smaller size of SER vacuolations (Fig. 12) and finally group (8) sections of those animals that received $\mathrm{DL}$ one hour before acetaminophen showed the smallest size of SER vacuolations (Fig. 13). 

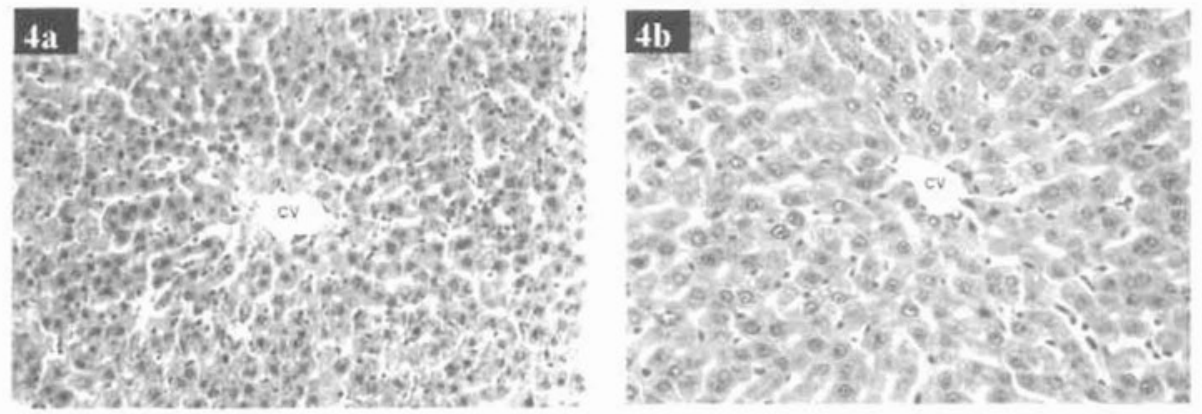

Fig. (4): Photomicrographs showing the classic hepatic lobules and central veins (CV) of negative control rats. (a- H. \& E.; x 200; b- H. \& E.; x 400).
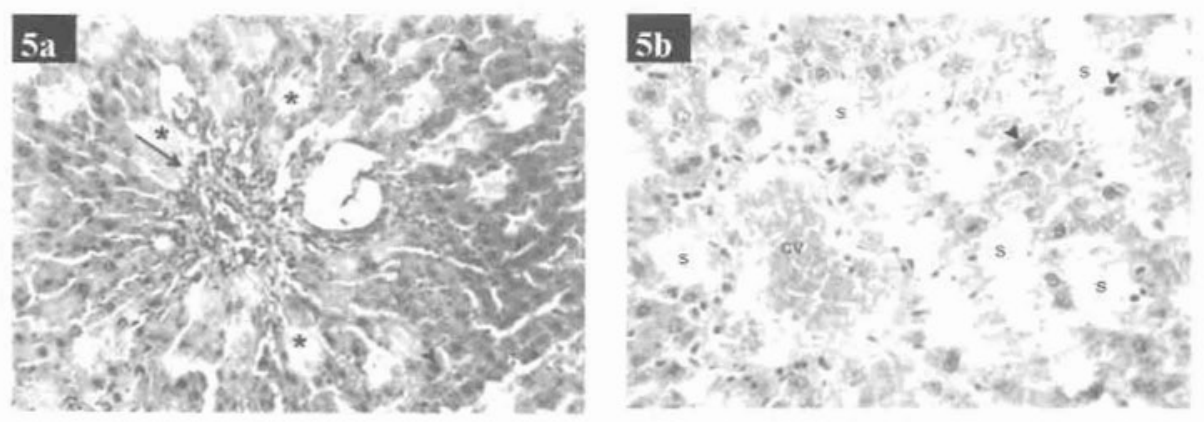

Fig. (5): Photomicrographs of sections from the livers of rats treated with acetaminophen alone:

(a) mononuclear cellular infiltration (arrow) at the portal tract area, and esinophilic degeneration and necrosis $\left(^{*}\right)$ in the cytoplasm of peripheral hepatocytes with pyknosis of some nuclei (arrowheads). (H. \& E.; x 200).

(b) congestion of the central vein (CV) and destruction of the hepatic lobular architecture with pyknotic nuclei (arrowheads) and sinusoidal dilatation (s). (H. \& E.; $x$ 200) 

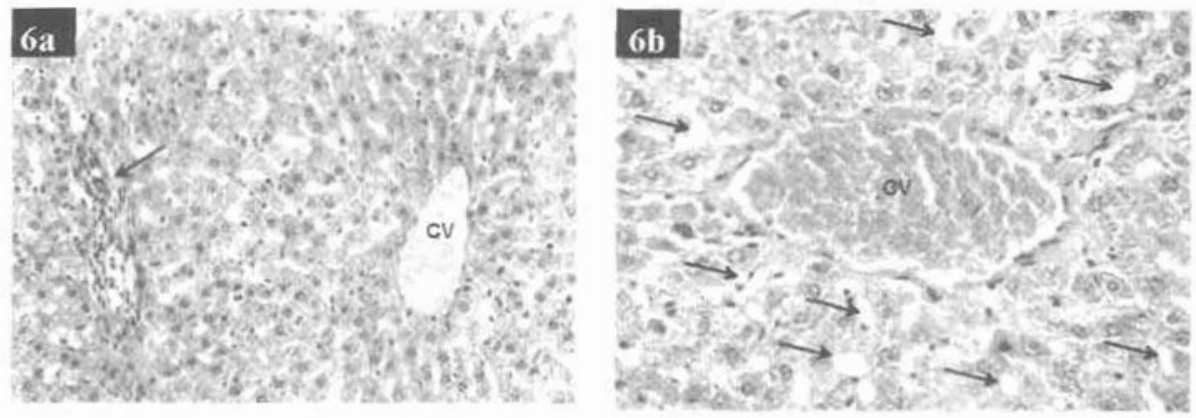

Fig. (6): Photomicrographs of sections from the livers of rats treated with nifedipine one hour before acetaminophen:

(a) mononuclear cellular infiltration at the portal tract (arrow). (H. \& E.; x 200)

(b) dilatation and congestion of the central vein (CV) and hydropic degeneration of hepatocytes which appeared vacuolated (arrows). (H. \& E.; $x$ 400)
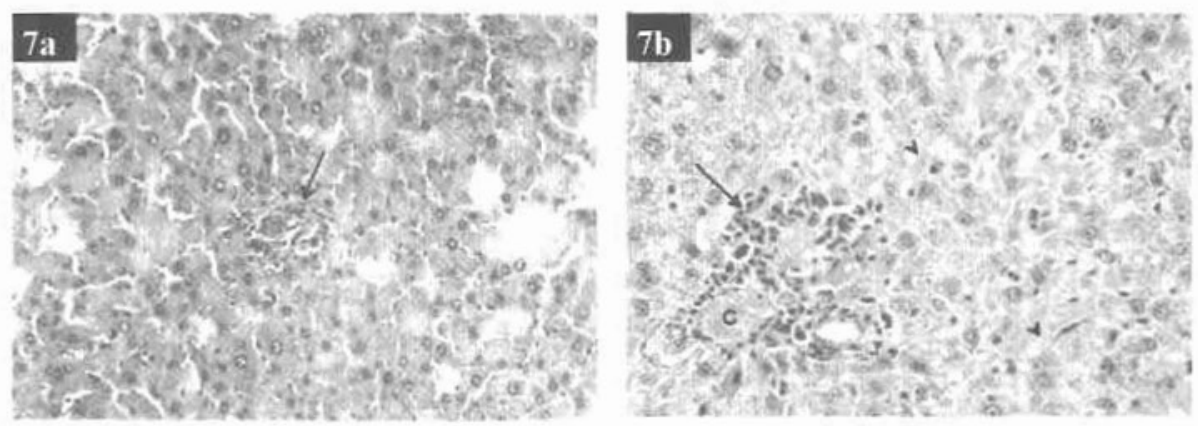

Fig. (7): Photomicrographs of sections from the livers of rats treated with verapamil one hour before acetaminophen:

(a) swollen hepatocytes with narrowed sinusoids and mononuclear cellular infiltration at the portal tract (arrow). (H. \& E.; x 200)

(b) mononuclear cellular infiltration at the portal tract (arrow) with congestion of a blood vessel (c) and hepatic sinusoids (arrowheads). (H. \& E.; x 400) 

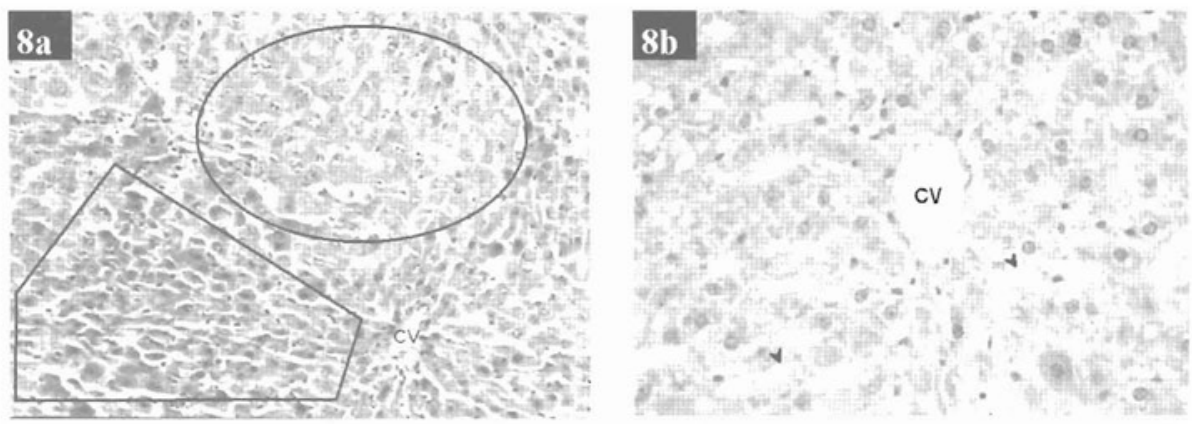

Fig. (8): Photomicrographs of sections from the livers of rats treated with diltiazem one hour before acetaminophen:

(a) patchy pathology in the form of few swollen hepatocytes (inside polygon) and other peripheral degenerated hepatocytes which appear vacuolated

(inside circle). (H. \& E.; x 200)

(b) exudates inside a central vein with dilatation of the sinusoids

(arrowheads) between the degenerated hepatocytes. (H. \& E.; x 400)

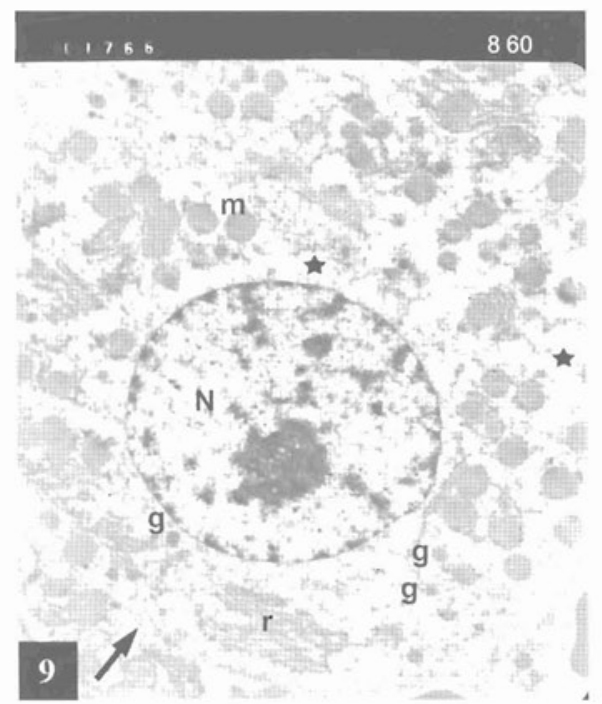

Fig. (9): Electron micrograph of a negative control hepatocyte showing the normal ultrastructure of the nucleus $(\mathrm{N})$, mitochondria $(\mathrm{m})$, rough endoplasmic reticulum $(\mathrm{r})$, glycogen $(\mathrm{g})$, smooth endoplasmic reticulum $\left(^{*}\right)$ and plasma membrane (arrow). (x 8600). 

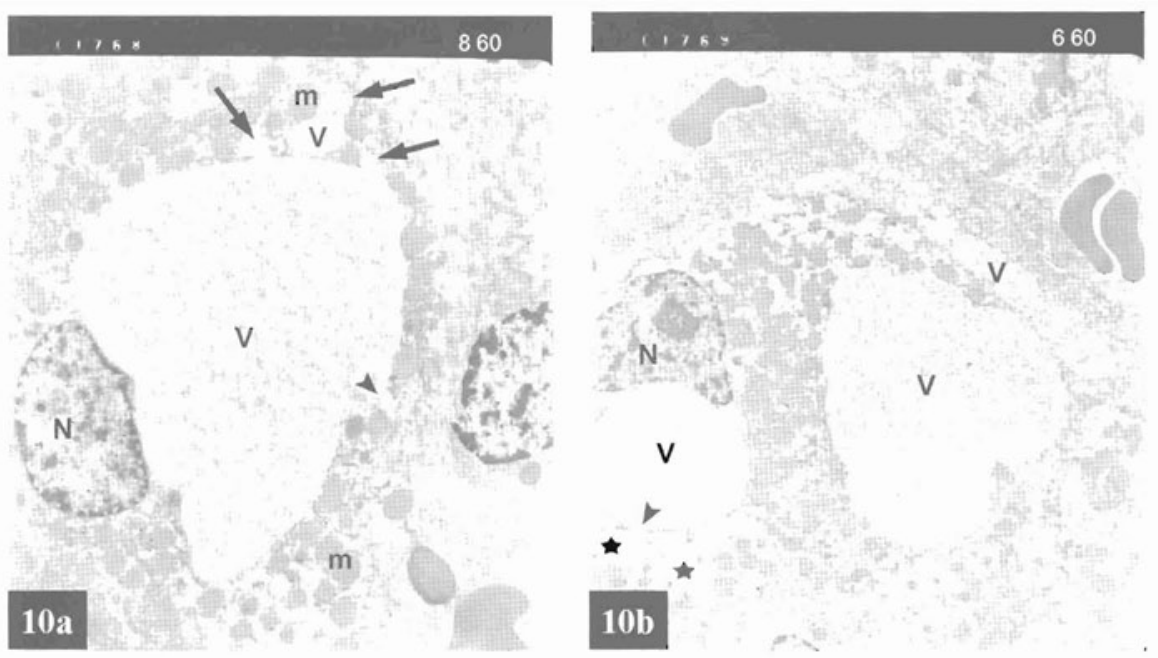

Fig. (10): Electron micrographs of sections from the livers of rats of group (2) which received acetaminophen alone showing:

(a) absence of glycogen, and the presence of large intracellular membrane-bound vacuole $(\mathrm{V})$, impinging on the nucleus $(\mathrm{N})$. The vacuole appears to contain loosely-packed electron-dense amorphous material. Note the communication (arrowhead) between the smooth endoplasmic canalicular system and the large intracellular vacuole. The plasma membrane was unapparent. Note the presence of a few lipid droplets (arrows). (x 8600)

(b) large intracellular membrane-bound vacuoles (V), one of them impinging on the nucleus $(\mathrm{N})$. The vacuoles contain loosely-packed electrondense amorphous material and appear to communicate (arrowhead) with the smooth endoplasmic canalicular system. (*)The plasma membrane was also unapparent. (x 6600)

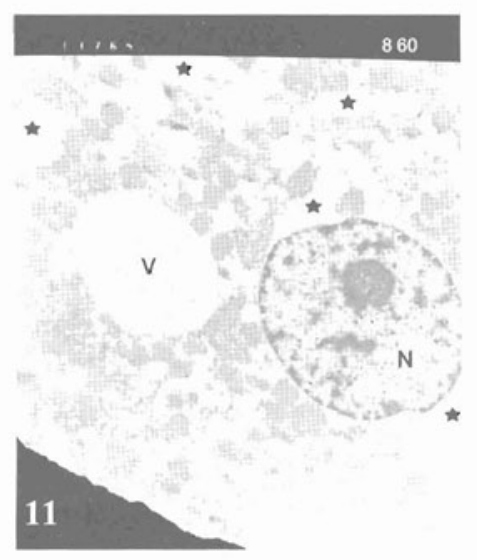

Fig. (11): Electron micrograph of a section from the liver of a rat of group (6) which received NF one hour before acetaminophen showing smaller size of the intracellular vacuoles $(V)$ than those of Figs. 10-a and 10-b. (x 8600) 


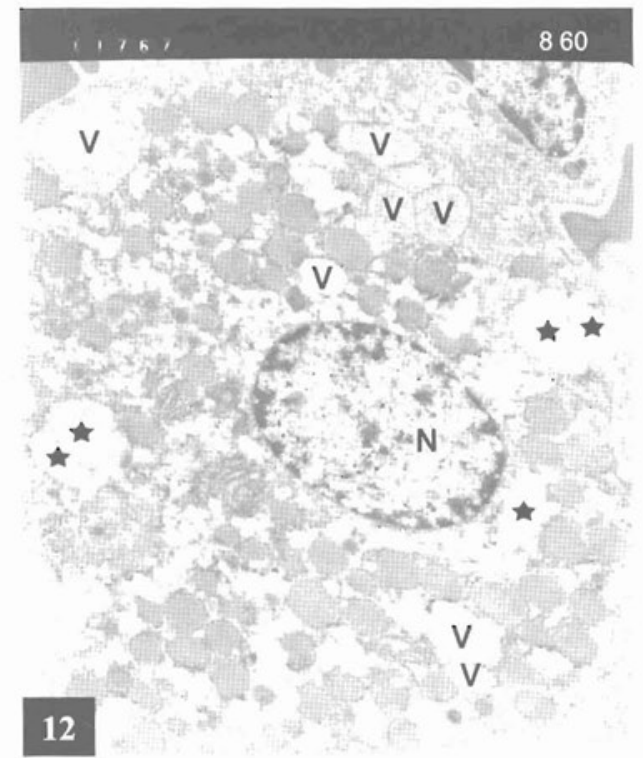

860

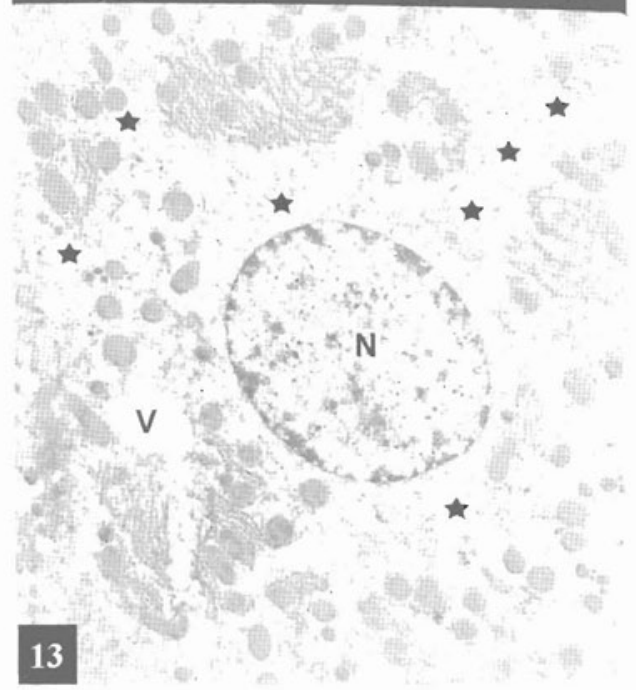

Fig. (12): Electron micrograph of a section from the liver of a rat of group (7) which received $V$ one hour before acetaminophen showing even smaller size of the intracellular vacuoles (V) than the previous electron micrographs. Note the presence dilatations of SER (*) (x 8600)

Fig. (13): Electron micrograph of a section from the liver of a rat of group (8) which received DL one hour before acetaminophen showing the smallest size of intracellular vacuoles (V) in addition to the presence of prominent smooth endoplasmic canalicular system $\left({ }^{*}\right) \quad(\times 8600)$. 


\section{DISCUSSION}

The results of this study showed that NF, V and DL, administered one hour before acetaminophen, improved the survival rates of rats and significantly decreased acetaminophen-induced hepatic damage measured by serum aminotransferases, liver weights and liver histology. These results are in agreement with the study of Thibault et al. (1991) who showed that 1 hour pretreatment of rat hepatocytes with calcium channel blocking agents protected cells against acetaminophen cytotoxicity, with the study of Satorres et al. (1995) who showed that diltiazem had a protective effect of against acetaminophen hepatotoxicity in mice, and with the study of Dimova et al. (1995) who showed that 1 hour pretreatment of mice with NF, V, DL and trifluoperazine protected against acetaminophen hepatotoxicity measured by AST and liver weights. However, in Dimova et al. (1995) study, the survival rates were significantly improved with $V$ and $D L$ but not with NF. These different results may be related to differences in methodology, particularly doses of the tested drugs, methods of their administration, and species of animals tested.

There is evidence that the inhibition of cytochrome P450-dependent drug-metabolizing enzymes by piperonil butoxide (Jollow et al., 1973), metyrapone (Fossa et al., 1979), potassium ethylxanthogenate (Dimova and Stoytchev, 1990), diallyl sulfide (Hu et al., 1996), cimetidine (Murase et al., 1986; Al-Mustafa et al., 1997), 2-(allylthio)pyrazine (Kim et al., 1997) or Phenethyl isothiocyanate (Li et al., 1997) prevents acetaminophen toxicity due to reduced synthesis of the acetaminophen reactive metabolite. On the other hand, the inducers of the microsomal monooxygenases (Phenobarbital, 3-methylcholanthrene and ethanol, chronically) increase the lethality of the experimental animals and the severity of the liver necrosis due to increased synthesis of the acetaminophen reactive metabolite (Carpenter et al., 1996; Lin and Lu, 1998; Draganov et al., 2000).

In the present study, NF significantly increased cytochrome P450 content, while $V$ and DL showed no significant changes. These results are in agreement with the studies of Dimova et al. (1995) and Zangar et al. (1999). Also, in the present study, DL significantly decreased lipid peroxidation, while NF and $V$ showed no significant changes. These results were in agreement with the studies of Koleva and Stoytchev (1991) and Dimova et al. (1995). It is possible that because of these results DL showed the most protective effect followed by $V$ then NF, although these effects were pronounced histologically but insignificant in other tests.

The previous observations correlate with the histological results where $\mathrm{DL}$ was found to provide the greatest degree of protection against acute acetaminophen hepatotoxicity followed by $\vee$ then NF. The histological changes of hepatotoxicity were least with $\mathrm{DL}$ pretreatment followed by $\mathrm{V}$ 
then by NF. The hepatotoxic changes of acetaminophen observed in this study are in agreement with those observed by earlier studies such as Portman et al. (1975) and Gerber et al. (1980) who considered these hepatotoxic changes a classic example of centrilobular esinophilic coagulative necrosis. In severe cases, they reported that the necrosis bridged over the centrilobular areas or extensively involved much of the lobule with focal sparing of the peripheral parenchyma. They noted that outside the necrotic zone, inflammation was sparse with only mild fatty changes or mononuclear portal infiltrates were sometimes seen. At the electron microscopy level, Datta and Bhattacharyya (2001) considered that the dilatation and vacuolations of SER were the characteristic cytotoxic injury induced by acetaminophen. So these criteria were used in this study to assess and compare whatever protective effect that might be provided by the calcium channel blocking agents against acute acetaminophen induced hepatotoxicity. In this respect, the degree of SER dilatation and vacuolations were least with DL pretreatment followed by $V$ then NF. Thus it was clear enough by both light and electron microscopy that $\mathrm{Ca}^{2+}$ channel blocking agents have diminished the acute acetaminophen hepatotoxic effects.

In the present study, NF, $V$ and $D L$ showed no significant changes on either hepatic reduced glutathione (GSH) or the GSH depletion provoked by the toxic dose of acetaminophen. These results are in agreement with the study of Dimova et al. (1995). Calcium channel blocking agents act by reducing the initial entry of calcium into the liver cells. Landon et al. (1986) have found that the protective action of NF, V and chlorpromazine against acetaminophen-induced toxicity is associated with a reduction in liver cell calcium. Bruschi and Priestly (1990) suggested that the mobilization of intracellular $\mathrm{Ca}^{2+}$ may be an important early event in acetaminopheninduced hepatotoxicity. Boobis et al. (1990) provided a direct evidence that an increase in intracellular calcium is the cause of cell death in hepatocytes exposed to acetaminophen. Dimova et al. (1995) reported that it is still unclear whether the disturbance of calcium homeostasis involved in the acetaminophen-induced cell necrosis results from an influx of extracellular calcium into the cell or whether this disturbance is the consequence of a release of internal calcium stores from subcellular organelles like the endoplasmic reticulum or the mitochondrion. Beales et al. (1985) have documented that external free calcium is not essential for the development of acetaminophen cell injury in liver slices and hepatocytes. Thibault et al. (1991) suggested that the influx of extracellular $\mathrm{Ca}^{2+}$ into the cells could have a role in the genesis of hepatocyte injury by acetaminophen. A very important mechanism of action of calcium channel blocking agents is the dilatation of blood vessels which enhances local vascular circulation, such an action in the liver could enhances the oxygenation of the centrilobular region of the liver lobule that appears to be susceptible to acetaminophen. This might contribute to the protective effect of calcium channel blockers against acetaminophen-induced hepatotoxicity (Dimova et al., 1995). 
The results of this study suggest that NF, $V$ and $D L$ are effective in reducing acetaminophen hepatotoxicity in rats. In conclusion, NF, V and DL might represent a useful addition to the treatment modalities after acetaminophen overdosage. Further work is recommended to demonstrate their efficacy as adjunctive treatment of acetaminophen toxicity in humans.

\section{SUMMARY}

There is evidence that an increase in cytosolic calcium $\left(\mathrm{Ca}^{2+}\right)$ is involved in acetaminophen hepatotoxicity. The protective effects of $\mathrm{Ca}^{2+}$ channel blocking agents nifedipine (NF), verapamil (V) and diltiazem (DL) on acute acetaminophen hepatotoxicity were studied in adult male albino rats toxicologically as well as by light and electron microscopic studies.

The results showed that pretreatment with each of NF, $V$ and $D L$, one hour before acetaminophen, significantly decreased acetaminopheninduced hepatic damage measured by serum aminotransferases, liver weights and liver histology. Histologically, DL offered the greatest degree of protection followed by $V$ then NF. Nifedipine significantly increased cytochrome $P 450$ content, while $V$ and $D L$ showed no significant changes. Diltiazem significantly decreased lipid peroxidation, while NF and $V$ showed no significant changes. Nifedipine, $V$ and $D L$ showed no significant changes on either hepatic reduced glutathione (GSH) or the GSH depletion provoked by the toxic dose of acetaminophen.

The possible mechanism of the protective effects of NF, $V$ and $D L$ on the acetaminophen-induced toxicity is discussed.

\section{REFERENCES}

1. Abbott, F.V. and Fraser, M.E. (1998): Use and abuse of over-thecounter analgesic preparations. J. Psychiat. Neurosci., 23(1): 13.

2. Al-Mustafa, Z.H.; Al-Ali, A.K.; Qaw, F.S. and Abdul-Cader, Z. (1997): Cimetidine enhances the hepatoprotective action of $\mathrm{N}$-acetylcysteine in mice treated with toxic doses of paracetamol. Toxicol., 121(3): 223.

3. Anundi, I.; Lahteenmaki, T.; Rundgren, M.; Moldeus, P. and Lindros, K.O. (1993): Zonation of acetaminophen metabolism and cytochrome P450 2E1-mediated toxicity studied in isolated periportal and perivenous hepatocytes. Biochem. Pharmacol., 45(6): 1251.

4. Beales, D,; Hue, D.P. and McLean, A.E.M. (1985): Lipid peroxidation, protein synthesis and protection by calcium EDTA in paracetamol injury to isolated hepatocytes. Biochem. Pharmacol., 34: 19. 
5. Boobis, A.R.; Fawthrop, J. and Davies, D.S. (1989): Mechanisms of cell death. Trends. Pharmacol. Sci., 10: 275.

6. Boobis, A.R.; Seddon, C.E.; Nasseri-Sina, P. and Davies, D.S. (1990): Evidence for a direct role of intracellular calcium in paracetamol toxicity. Biochem. Pharmacol., 39: 1277.

7. Boyd, E.M. and Bereczky, G.M. (1966): Liver necrosis from paracetamol. Br. J. Pharmac. Chemother., 26: 606.

8. Bruschi, S.A. and Priestly, B.G. (1990): Implantation of alteratios of intracellular calcium ion homeostasis in the advent of paracetamol-induced cytotoxicity in primary mouse hepatocyte monolayer cultures. Toxicol. in Vitro, 4: 743.

9. Buege, J.A. and Aust, S.D. (1978): Microsomal lipid peroxidation. In: Fleisher, S.; Packer, L. (eds) Meth. Enzymol, . Academic Press, New York, vol. 52:302.

10. Carpenter, S.P.; Lasker, J.M. and Raucy, J.L. (1996): Expression, induction, and catalytic activity of the ethanol-inducible cytochrome P450 (CYP2E1) in human fetal liver and hepatocytes. Mol. Pharmacol. 49(2): 260.

11. Clarke, E.G.C. (1974): Isolation and identification of drugs. The Pharmaceutical Press. 1: 466.

12. Cobreros, A.; Sainz, L.; Lasheras, B. and Cenarruzabeitia, E. (1997): Hepatotoxicity of ethanol - protective effect of calcium channel blockers in isolated hepatocytes. Liver, 172: 76.

13. Cohen, S.D. and Khairallah, E.A. (1997): Selective protein arylation and acetaminophen-induced hepatotoxicity. Drug Metab. Rev. 29(1-2): 59.

14. Crenesse, D.; Hugues, M.; Ferre, C.; Poiree, J.C.; Benoliel, J.; Dolisi, C. and Gugenheim, J. (1999): Inhibition of calcium influx during hypoxia/reoxygenation in primary cultured rat hepatocytes. Pharmacology, $\mathbf{5 8}$ (3): 160 .

15. Datta, S. and Bhattacharyya, P. (2001): Effect of a herbal protein $\mathrm{Cl}$ 1 , purified from Cajanus indicus on the ultrastructural study of hepatocytes, in models of liver failure in mice. J. Ethnopharmacol., 77(1):11.

16. Dimova, S.; Koleva, M.; Rangelova, D. and Stoytchev, T. (1995): Effect of nifedipine, verapamil, diltiazem and trifluoperazine on acetaminophen toxicity in mice. Arch. Toxicol., 70: 112. 
17. Dimova, S. and Stoytchev, T. (1990): Effect of potassium ethylxnthogenate on acetaminophen hepatotoxicity in mice. Acta Physiol. Pharmacol. Bulg., 16 (4): 23.

18. Dixon, M.F.; Nimmo, J. and Prescott, L.F. (1971): Experimental paracetamol-induced hepatic necrosis: a histopathological study. J. Path., 103:225.

19. Draganov, P.; Durrence, H.; Cox, C. and Reuben, A. (2000): Alcoholacetaminophen syndrome: Even moderate social drinkers are at risk. Postgrad. Med. 107(1): 189.

20. Drury, R.R. and Wallington, E.A. (1980): Carleton's histological techniques. $5^{\text {th }}$ ed., Oxford University Press, London, New York, Toronto, 241.

21. Ellouk-Achard, S.; Mawet, E.; Thibault, N.; Dutertre-Catella, H.; Thevenin, M. and Claude, J.R. (1995): Protective effect of nifedipine against cytotoxicity and intracellular calcium alterations induced by acetaminophen in rat hepatocyte cultures. Drug Chem. Toxicol., 18(2-3): 105.

22. Flaherty, J.H. (1998): Commonly prescribed and over-the-counter medications: Causes of confusion (review). Clinics in Geriat. Med. 14(1): 101.

23. Fossa, A.A.; Hadley, W.M. and Born, J.L. (1979): Decrease in acetaminophen toxicity in mice treated with metyrapone. Toxicol. Lett., 4: 379.

24. Gerber, M.A.; Kaufmann, H.; Klion, F. and Alpert, L.I. (1980): Acetaminophen associated hepatic injury. Report of two cases showing unusual portal tract reactions. Hum. Pathol. 11: 37.

25. Harman AW; Kyle ME; Serroni A and Farber JL (1991): The killing of cultured hepatocytes by $\mathrm{N}$-acetyl-p-benzoquinone imine (NAPQI) as a model of the cytotoxicity of acetaminophen. Biochem. Pharmacol. 41(8): 1111.

26. Hayat, M.A. (1970): Principle and Techniques of Electron Microscope: Biological Application. Van Nostrand Reinhold, New York, vol. I.

27. Hissin, P. and Hilf, R. (1976): A fluorimetric method for determination of oxidized and reduced glutathione in tissues. Anal. Biochem., 74: 214.

28. Hu, J.J.; Yoo, J.S.; Lin, M.; Wang, E.J. and Yang, C.S. (1996): Protective effects of diallyl sulfide on Acetaminophen-induced toxicities. Food Chem. Toxicol., 34(10): 963. 
29. Jollow, D.J.; Mitchell, J.R.; Potter, W.Z.; Davies, D.C.; Gillette, J.R. and Brodie, B.B. (1973): Acetaminophen-induced hepatic necrosis. II. Role of covalent binding in vivo. J. Pharmacol. Exp. Ther. 187: 195.

30. Kim, N.D.; Kwak, M.K. and Kim, S.G. (1997): Inhibition of cytochrome $P_{450} 2 E 1$ expression by 2 - (allylthio) pyrazine, a potential chemoprotective agent: hepatoprotective effects. Biochem. Pharmacol., 53(3): 261.

31. Koleva, M. and Stoytchev, T. (1995): Effect of nifedipine, verapamil and diltiazem on the enzyme-inducing activity of phenobarbital and betanaphthoflavone. Gen. Pharmacol., 26(1): 225.

32. Koleva, M. and Stoytchev, T. (1991): Effect of nifedipine, verapamil and diltiazem on drug-metabolizing enzyme systems after single administration in rats. Compt. Rend. Acad. Bulg. Sci., 44: 109.

33. Lauterburg, B.H. and Mitchell, J.R. (1982): Toxic doses of acetaminophen suppress hepatic glutathione synthesis in rats. Hepatol., 2: 8.

34. Li, Y.; Wang, E.J.; Chen, L.; Stein, A.P.; Reuhl, K.R. and Yang, C.S. (1997): Effects of phenethyl isothiocyanate on acetaminophen metabolism and hepatotoxicity in mice. Toxicol. Appl. Pharmacol., 144(2): 306-314.

35. Lin, J.H. and Lu, A.Y.H. (1998): Inhibition and Induction of cytochrome P450 and the clinical implications. Clin. Pharmacomkinet., 35(5): 361.

36. Landon, E.J.; Naukan, R.J. and Sastry, B.V. (1986): Effect of calcium channel blocking agents on calcium and centrilobular necrosis in the liver of rats treated with hepatotoxic agents. Biochem. Pharmacol., 35: 697.

37. Matthews, A.M.; Roberts, D.W.; Hinson, J.A. and Pumford, N.R. (1996): Acetaminophen-induced hepatotoxicity. Analysis of total covalent binding vs. specific binding to cysteine. Drug Metab. Dispos., 24(11): 1192.

38. Murase, T.; Hazama, H.; Okuno, H.; Shiozaki, Y. and Sameshima, Y. (1986): Effect of H2-receptor antagonists on acetaminophen-induced hepatic injury. Jpn. J. Pharmacol., 41:467.

39. Omura, T. and Sato, R. (1964): The carbon monooxide binding pigment of liver microsomes. I. Evidence for its haemoprotein nature. J. Biol. Chem., 239: 2370.

40. Orrenius, S.; McConkey, D.J.; Bellomo, G. and Nicotera, P. (1989): Role of $\mathrm{Ca}^{2+}$ in toxic cell killing. Trends Pharmacol. Sci., 10: 281. 
41. Portmann, B.; Talbot, I.C. and Day, D.W. (1975): Histopathological changes in the liver following a paracetamol overdose: Correlation with clinical and biochemical parameters. J. Pathol., 117:169.

41. Reitman, S. and Frankel, S. (1957): A colorimetric method for the determination of serum glutarnic oxaloacetic and glutamic pyruvic transaminases. Am. J. Clin. Pathol., 28:56.

42. Satorres, J.; Perez-Mateo, M.; Mayol, M.J.; Esteban, A. and Graells, M.L. (1995): Protective effect of diltiazem against acetaminophen hepatotoxicity in mice. Liver, 15(1): 16.

43. Thibault, N.; Peytavin, G. and Claude, J.R. (1991): Calcium channel blocking agents protect against acetaminophen-induced cytotoxicity in rat hepatocytes. J. Biochem. Toxicol., 6: 237.

44. Zangar, R.C.; Okita, J.R.; Hyesook, K.; Thomas, P.E.; Anderson, A.; Edwards, R.J.; Springer, D.L. and Okita, R.T. (1999): Effect of Calcium Channel Antagonists Nifedipine and Nicardipine on Rat Cytochrome P-450 2B and 3A Forms. J. Pharmacol. Exp. Ther., 290: 1436. 


\section{الملخص العربيى}

الاور الوقائي لعقاقير النيفديبين والقير اباميل والدلتيازم في التأثيرات

السامة الحادة للأسيتامينوفين على كبا الفأر الأبيض البالغ

* " أسامة محمد البراتى" - أشرف محمود فوزى كامل

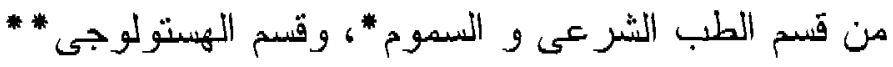

كلية الطب - جامعة القاهرة

حبث انه قد ثبت بالدليل ارتباط زيادة الكالسيوم داخل الذلايا بالتأثير ات الكبدية

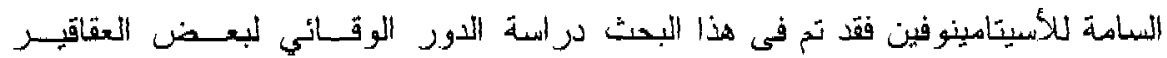

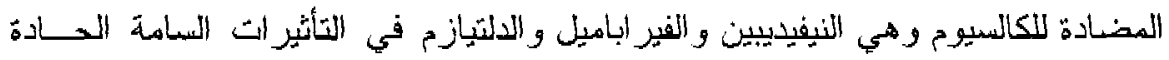

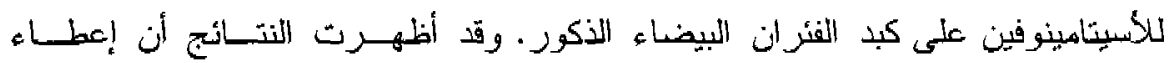

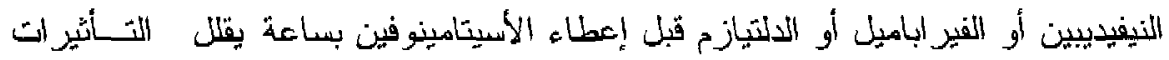

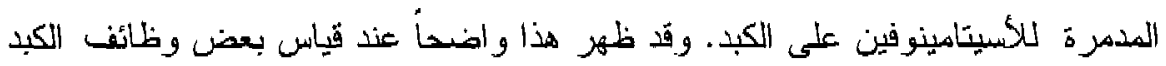

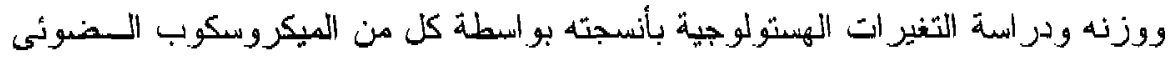

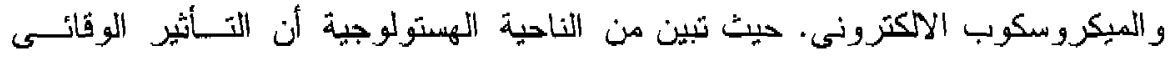

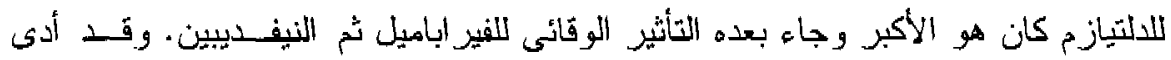

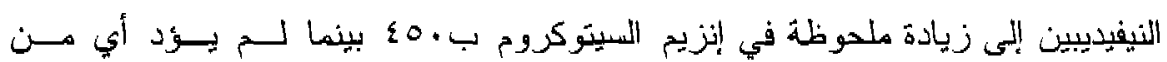

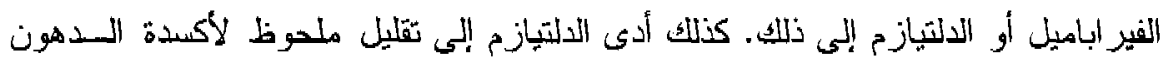

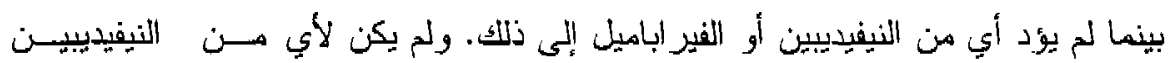

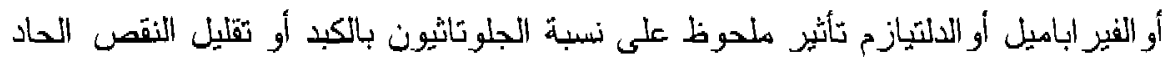

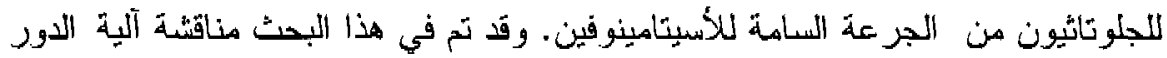
الوقائي للنيفيديبين و الفير اباميل و الدلتيازم في التأثير ات السامة للأسيتامينوفين.

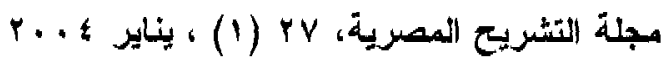

